\title{
Enhancement of the Circulating Antibody Secreting Cell Response in Human Diarrhea by a Human Lactobacillus Strain
}

\author{
MINNA KAILA, ERIKA ISOLAURI, ESA SOPPI, ELINA VIRTANEN, SEPPO LAINE, AND \\ HEIKKI ARVILOMMI
}

Department of Clinical Sciences, University of Tampere [M.K., E.I.] and Department of Clinical Microbiology, Division of Clinical Immunology, Tampere University Hospital [E.S., S.L.], Tampere, Finland and National Public Health Institute [E.V., H.A.], Turku, Finland

\begin{abstract}
Human Lactobacillus sp strain GG (Lactobacillus GG) administered during acute rotavirus diarrhea has been shown to promote clinical recovery. To elucidate the immune mechanisms behind such a favorable outcome, the ELISPOT (solid phase enzyme-linked immunospot) assay of Ig- and specific antibody-secreting cells among circulating lymphocytes was used, giving indirect evidence of the immunologic events in the gut. After rehydration, 39 children with acute rotavirus diarrhea, mean age 16 (SD 6) mo, randomly received either a Lactobacillus GG fermented milk product (study group) or a pasteurized yogurt (placebo group). The duration of diarrhea was significantly shorter in the study group than in the placebo group [mean 1.1 (SD 0.6) versus 2.5 (SD 1.4) d, $p=0.001$ ]. Lactobacillus GG therapy was associated with a significantly enhanced nonspecific humoral response during the acute phase of the infection, reflected in the IgG, IgA, and $\operatorname{IgM}$ Igsecreting cell numbers. At convalescence, $90 \%$ of the study group versus $46 \%$ of the placebo group had developed an IgA specific antibody-secreting cell response to rotavirus $(p=0.006)$. The results indicate that Lactobacillus GG promotes recovery from rotavirus diarrhea via augmentation of the local immune defense. Furthermore, specific IgA response to rotavirus is endorsed, which is possibly relevant in protection against reinfections. (Pediatr Res 32: 141-144, 1992)
\end{abstract}

\section{Abbreviations}

Lactobacillus GG, Lactobacillus sp strain GG BLG, $\beta$-lactoglobulin

CI, confidence interval

ISC, Ig-secreting cell

sASC, specific antibody-secreting cell

ELISPOT, solid phase enzyme-linked immunospot

Rotaviruses have emerged as a major cause of acute diarrhea in infants and children worldwide (1). The infection is characterized by vomiting, watery diarrhea, and fever. The main goal of treatment, correction of the dehydration, is achieved by oral rehydration. The issue of nutritional therapy in acute diarrhea is still an open question.

The nutritional state of the patient has a strong impact on the

Received September 6, 1991; accepted March 17, 1992.

Correspondence and reprint requests: Minna Kaila, M.D., University of Tampere, Department of Clinical Sciences, PO Box 607, 33101 Tampere, Finland

Supported by the Foundation for Nutrition Research and the E. Aaltonen Foundation. course of diarrhea. Malnutrition has been reported to increase the absorption of potentially harmful antigens (2) and to impair immune responses (3). A poor nutritional state may thus increase the risk of protracted diarrhea as well as enhance susceptibility to other infections and to gastrointestinal allergy. The nutritional state of even well-nourished infants deteriorates rapidly during diarrhea, either because of loss of appetite, deliberate withholding of oral feeds, or partial malabsorption caused by viral invasion of enterocytes (4).

Rapid reintroduction of oral feedings after rehydration has been advocated to counteract the potential hazards related to fasting during diarrhea (5). We have previously shown that rapid refeeding results in earlier cessation of diarrhea in well-nourished children; also, cow milk products are tolerated (6). A further shortening of diarrhea resulted from administration of human Lactobacillus strain (Lactobacillus GG, Gefilac, Valio Finnish Co-operative Dairies' Association, Helsinki, Finland) together with the rapid refeeding schedule (7). The mechanisms behind such a favorable outcome remain poorly understood. The effect of nutritional therapy may be immunologically mediated and may prove important in eradicating enteric infections in the immunocompromised host.

The objective of the present study was to evaluate the effect of Lactobacillus GG on the intestinal immune response triggered by rotavirus infection in well-nourished children. For this purpose, we used the ELISPOT assay, which measures ISC and sASC among circulating lymphocytes. These cells are arrested during their maturation cycle in peripheral blood, giving indirect evidence of gut local immune response (8-10).

\section{MATERIALS AND METHODS}

Patients. Forty-four well-nourished children (33.4\% female), between 7 and $37 \mathrm{mo}$ of age, were enrolled in the present study. They were admitted for acute gastroenteritis of less than $7 \mathrm{~d}$ duration at the Department of Pediatrics, Tampere University Hospital, during a rotavirus epidemic.

Informed consent was obtained from the patients' parents, and the protocol was approved by the hospital's Committee on Ethical Practice.

Management and samples. Upon admission, the children were weighed and clinically examined. The severity of dehydration (\%) was estimated. The children were treated according to standard practice: oral rehydration was accomplished in $6 \mathrm{~h}$ with a solution containing $\mathrm{Na}^{+} 60 \mathrm{mmol} / \mathrm{L}$ and glucose $144 \mathrm{mmol} / \mathrm{L}$ (Osmosal Novum, Leiras, Turku, Finland) given at twice the estimated fluid loss with a minimum of $30 \mathrm{~mL} / \mathrm{kg}$ body weight. The patients were weighed daily. The attending nurses followed the quality (characterized as watery, loose, or solid) and number of stools and vomitus. The duration of diarrhea was counted 
from the last appearance of watery stools. The patients were discharged according to the clinical judgment of the attending physician. They were seen 3 wk later or sooner if diarrhea recurred.

Blood was drawn on admission for determination of acid-base balance and serum sodium concentration. For the ELISPOT assay, blood in heparin was drawn $1 \mathrm{~d}$ after admission and $3 \mathrm{wk}$ later. At convalescence, blood was also drawn for measurement of serum cow milk and rotavirus antibodies.

Feces were tested for rotavirus antigen with an enzyme immunoassay (Rotazyme, Abbott Laboratories, North Chicago, IL) and cultured for Salmonella, Shigella, Campylobacter, and Yersinia.

Dietary therapy. After rehydration, alimentation appropriate for age was resumed, excluding only fermented milk products. Infants still totally breast-fed were not included in the study.

The patients randomly received one of two dietary regimens for $5 \mathrm{~d}$ in addition to the rapid refeeding schedule. The study group received $10^{10}-10^{11}$ colony-forming units Lactobacillus $\mathrm{GG}$, as a fermented milk product, $125 \mathrm{~g}$ twice daily. The placebo group received a fermented-then-pasteurized yogurt, with $<10^{3}$ colony-forming units lactic acid bacteria, $125 \mathrm{~g}$ twice daily. Both Lactobacillus GG and the placebo yogurt were supplied by the Research and Development Centre of Valio Finnish Co-operative Dairies' Association, Helsinki, Finland.

Determination of the immune response. Mononuclear cells containing mainly lymphocytes were obtained by FicollPaque (Pharmacia, Uppsala, Sweden) centrifugation of the heparinized blood. The total number of ISC (antigen-nonspecific immune response) and SASC (antigen-specific immune response) were determined by the ELISPOT method, as described previously $(8-10)$. We and others have shown that the number of these lymphocytes in peripheral blood reaches a maximum 6-8 d after oral administration of antigen (8-12).

In brief, cells are incubated in antigen-coated, flat-bottomed, 96-well microtiter plates (Immunoplate R I, a/s Nunc, Roskilde, Denmark) to allow the antibodies secreted by them to react with the antigen near them. The antibodies from each cell are visualized by application of enzyme-labeled antisera followed by a substrate-agarose overlay and by observing the colored spots.

For determination of ISC, coating of the plates was done with rabbit Ig to human IgA ( $\alpha$-chain) and IgM ( $\mu$-chain) (Dakopatts a/s, Roskilde, Denmark), goat anti-human IgG ( $\gamma$-chain specific) $\mathrm{F}\left(\mathrm{ab}^{\prime}\right)^{2}$ fragment of antibody, goat anti-human $\operatorname{IgG}(\gamma$-chain specific), IgA ( $\alpha$-chain specific), and $\operatorname{IgM}$ ( $\mu$-chain specific) alkaline phosphatase conjugate (Sigma Chemical Co., St. Louis, MO). For determination of sASC to rotavirus, the coating was done in two stages. First, the wells were coated for $2 \mathrm{~h}$ at $37^{\circ} \mathrm{C}$ or overnight at $4^{\circ} \mathrm{C}$ with rabbit antirotavirus (human) (Dakopatts a/s, Glostrup, Denmark). After washing the wells with PBS- $0.05 \%$ Tween 20 , rotavirus antigen (for the complement fixation test, Behringwerke AB, Marburg, Germany) was applied for $2 \mathrm{~h}$ at $37^{\circ} \mathrm{C}$. This two-stage coating was found superior to mere rotavirus antigen coating in preliminary ELISA tests on rotavirus-positive and -negative sera. To determine sASC against BLG, wells were coated with BLG as described in elsewhere (13). 5-bromo-4chloro-3-indolylphosphate $p$-toluidine salt was used as substrate for alkaline phosphatase. It is considered an immune response if $>0.5 \mathrm{sASC} / 10^{6}$ cells are detected (13).

Serum antibodies against cow milk antigens, BLG A and B, $\alpha$-casein, $\alpha$-lactalbumin, BSA, and total milk protein, reflecting the systemic immune response, were determined by ELISA (14). In brief, the antigens were diluted to appropriate concentrations. Microtiter plate wells (Nunc-Immuno plate MaxiSorp, Nunc) were coated with the antigen solution. Test sera were added and, after incubation and washing, antihuman antisera conjugated with alkaline phosphatase were added. Absorbances were determined. Serum rotavirus antibodies were measured using a complement fixation test.

Statistical analyses. Because of skewed distributions of ISC and sASC numbers, logarithmic transformation was used and the numbers are thus given as geometric mean $(95 \% \mathrm{CI})$. Twotailed independent $t$ test was applied for comparison of differences. Paired $t$ test was used for comparing repeated measurements. The $\chi^{2}$ test was applied to determine differences in proportions. Spearman rank correlation coefficient was applied to determine the significance of association between age and the ELISPOT response.

\section{RESULTS}

Clinical characteristics of patients. Altogether, 39 (88\%) patients were rotavirus-positive, and they formed the actual study $(n=22)$ and placebo $(n=17)$ groups. The clinical picture upon admission was comparable in both groups with iso-osmolal dehydration and metabolic acidosis (Table 1). The ages of the patients in the two groups were comparable, with the difference between means being 3.2 mo $(95 \% \mathrm{CI}-0.6,7.0)$.

Clinical outcome. During a short stay in hospital, the patients were rehydrated and realimented, with weight gain resulting in both groups (Table 2 ). The duration of diarrhea was significantly reduced in the study group compared to the placebo group. During follow-up, there were no recurrences of diarrhea.

Antigen-nonspecific immune response. A prominent ISC response was measured during the acute phase of diarrhea in both groups, especially in cells secreting IgM (Fig. 1). This transient response in the study group was almost twice that in the placebo group in all Ig classes. At the convalescent phase, the difference between the two groups was no longer seen. The magnitude of the ISC responses did not correlate with age; for IgM ISC, rho = 0.09 and $p=0.65$.

Antigen-specific immune response to rotavirus. During diarrhea, patients in both the study group and the placebo group showed a similar sASC response to rotavirus in IgM class $[95$ (95\% CI 46, 198) and $82(95 \%$ CI 32,210$)$ sASC $/ 10^{6}$ cells,

Table 1. Clinical characteristics on admission of patients hospitalized for acute rotavirus gastroenteritis receiving rapid realimentation and either Lactobacillus $G G$ (study group) or placebo yogurt

\begin{tabular}{|c|c|c|c|c|c|}
\hline & \multicolumn{2}{|c|}{$\begin{array}{l}\text { Study group } \\
\quad(n=22)\end{array}$} & \multicolumn{2}{|c|}{$\begin{array}{l}\text { Placebo group } \\
\quad(n=17)\end{array}$} & \multirow{2}{*}{$\begin{array}{c}t \text { test } \\
p\end{array}$} \\
\hline & Mean & (SD) & Mean & $(\mathrm{SD})$ & \\
\hline Age (mo) & 17.5 & $(6.5)$ & 14.3 & (4.4) & 0.09 \\
\hline $\begin{array}{l}\text { Weight on admis- } \\
\text { sion }(\mathrm{g})\end{array}$ & 10134 & $(1920)$ & 9660 & $(1990)$ & 0.46 \\
\hline Dehydration (\%) & 4.7 & $(1.6)$ & 5.0 & $(2.8)$ & 0.54 \\
\hline $\begin{array}{l}\text { Base excess } \\
\qquad(\mathrm{mmol} / \mathrm{L})\end{array}$ & -8.5 & (3.8) & -7.2 & $(3.2)$ & 0.37 \\
\hline $\begin{array}{l}\text { Serum sodium } \\
(\mathrm{mmol} / \mathrm{L})\end{array}$ & 138 & (3) & 138 & (4) & 0.77 \\
\hline
\end{tabular}

Table 2. Clinical outcome of patients with acute rotavirus diarrhea during hospitalization given either Lactobacillus $G G$ (study group) or placebo yogurt

\begin{tabular}{lccc}
\hline & $\begin{array}{c}\text { Study group } \\
(n=22)\end{array}$ & $\begin{array}{c}\text { Placebo group } \\
(n=17)\end{array}$ & $p$ \\
\hline Weight gain $(\mathrm{g})^{*}$ & $285(114,711)$ & $275(167,454)$ & $0.95 \dagger$ \\
Diarrheal stools $(\%) \ddagger$ & & & \\
$\quad$ Day 1 & 91 & 94 & \\
Day 3 & 9 & 53 & $0.002 \S$ \\
Duration of diarrhea (d)\| & $1.1(0.6)$ & $2.5(1.4)$ & $0.001 \dagger$ \\
\hline
\end{tabular}

* Geometric mean $(95 \% \mathrm{CI})$.

$\dagger t$ test.

$\ddagger \%$ of patients.

$\S \chi^{2}$ test.

\| Mean (SD). 


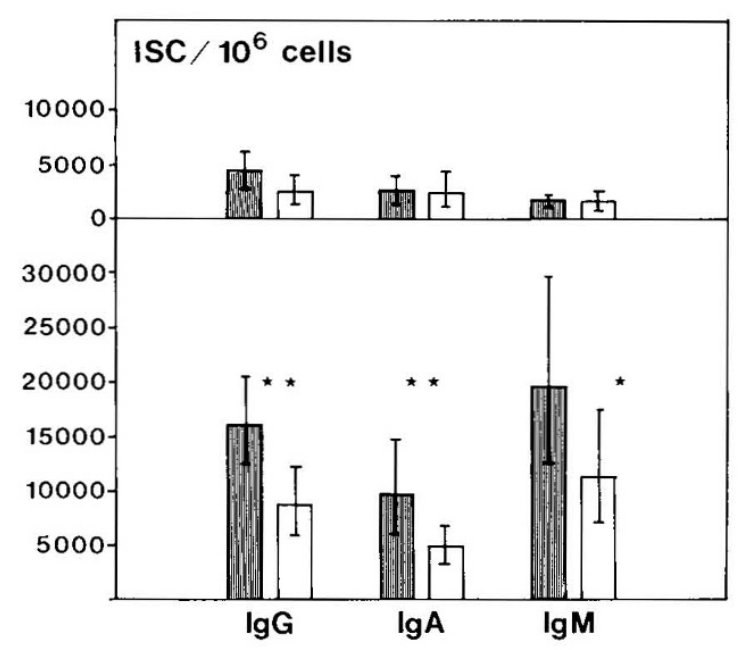

Fig. 1. The total number of ISC $/ 10^{6}$ cells during the diarrheal phase of rotavirus infection (lower panel) and 3 wk later (upper panel). The column denotes the mean and the vertical line is the $95 \% \mathrm{CI}$. The study group (shaded column) received Lactobacillus GG $(n=20)$ and the placebo group (open column) received a placebo yogurt $(n=13) .^{*}, p<$ $0.05 ; * *, p<0.01$.

respectively; $p=0.79]$. Three wk later, the numbers were low in both groups: $5(95 \%$ CI 2,12$)$ and $8(95 \%$ CI 3,17$) \mathrm{sASC} / 10^{6}$ cells. The numbers of IgG sASC to rotavirus were low in both groups in the acute phase [9 $(95 \%$ CI 2,52$)$ versus $3(95 \%$ CI 1 , 14) $\mathrm{sASC} / 10^{6}$ cells] as well as in the convalescent phase [4 $(95 \%$ CI 1,12$)$ versus $4(95 \% \mathrm{CI} 0.2,54) \mathrm{sASC} / 10^{6}$ cells].

The numbers of IgA sASC to rotavirus were comparably low in the study and placebo groups in the acute phase [0.6 $(95 \% \mathrm{CI}$ $0.1,4)$ versus $0.2(95 \%$ CI $0.02,3) \mathrm{sASC} / 10^{6}$ cells. At convalescence, the number of IgA sASC to rotavirus was significantly higher in the study group than in the placebo group (Fig. 2). The (ln) difference $(95 \% \mathrm{CI})$ between means was $3(95 \% \mathrm{CI} 0.4,5.6)$ sASC $/ 10^{6}$ cells. Altogether, 18 of 20 patients $(90 \%)$ in the study group had developed an IgA sASC response to rotavirus, compared to six of $13(46 \%)$ in the placebo group $(p=0.006)$.

The titers of serum antibodies against rotavirus were equal in the two groups: the median was 8 (range $0-16$ ) in the study group and 8 (range 0-512) in the placebo group.

Antigen-specific immune response to cow milk antigens. During the acute phase of rotavirus infection, an IgM sASC response to BLG was measured in both the study group and the placebo group [140 (95\% CI 62, 315) versus $104(95 \%$ CI 36, 304) sASC/ $10^{6}$ cells], and in the convalescent phase the response was 13 $\left(95 \%\right.$ CI 8, 21) versus $11\left(95 \%\right.$ CI 5, 28) sASC $/ 10^{6}$ cells, respectively. Compared to this, the response in the IgG class was low [ $2(95 \% \mathrm{CI} 0.6,7)$ versus $1(95 \% \mathrm{CI} 0.4,4) \mathrm{sASC} / 10^{6}$ cells in the acute phase and $0.2(95 \%$ CI $0.1,0.6)$ versus $1(95 \%$ CI $0.3,3)$ $\mathrm{sASC} / 10^{6}$ cells in the convalescent phase in the study and placebo groups, respectively], as was that in the IgA class [2 (95\% CI 0.5, 12) versus $2(95 \% \mathrm{CI} 0.4,7) \mathrm{sASC} / 10^{6}$ cells in the acute phase and $1(95 \% \mathrm{CI} 0.3,2)$ versus $2(95 \% \mathrm{CI} 0.5,6) \mathrm{sASC} / 10^{6}$ cells in the convalescent phase in the study and placebo groups, respectively].

Low levels of serum antibodies of isotypes IgG, IgA, and IgM against BLG A and B (Table 3) were detected in both the study group and the placebo group at convalescence. The levels of serum antibodies against $\alpha$-casein, $\alpha$-lactalbumin, BSA, and whole cow milk were also low and were not different in the two groups (data not shown).

\section{DISCUSSION}

The results of the present study indicate that Lactobacillus GG potentiates gut immune response to rotavirus and suggest that it

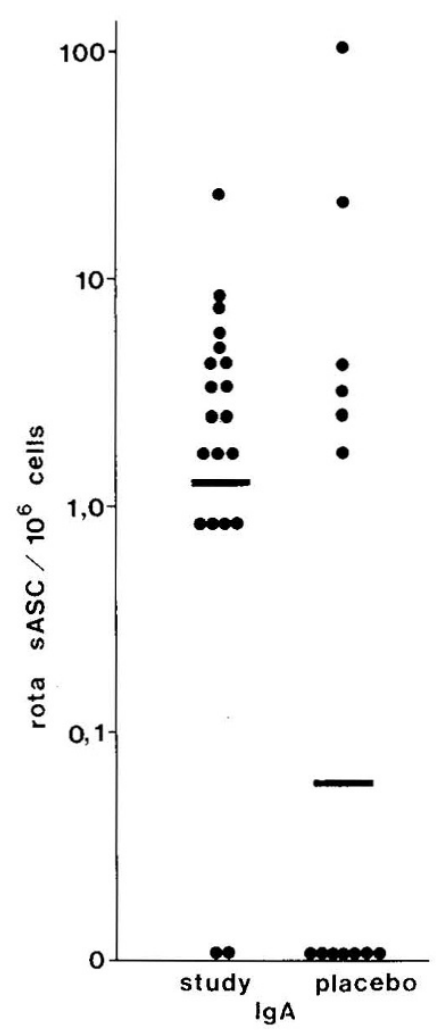

Fig. 2. The number of IgA sASC against rotavirus during the convalescent phase. The study group received Lactobacillus GG and the placebo group received a placebo yogurt. Points represent individual patients, horizontal lines means. Logarithmic scale.

Table 3. The serum levels (expressed as absorbances) of antibodies of different isotypes (IgG, $\operatorname{Ig} A$, and $\operatorname{Ig} M$ ) to $B L G A$ and $B$ in patients having had rotavirus diarrhea and having received either Lactobacillus $G G$ [study group $(n=19)]$ or placebo yogurt $(n=12)^{*}$

\begin{tabular}{|c|c|c|c|c|c|c|}
\hline & \multicolumn{2}{|c|}{$\operatorname{IgG}$} & \multicolumn{2}{|c|}{$\operatorname{IgA}$} & \multicolumn{2}{|c|}{$\operatorname{IgM}$} \\
\hline & BLG A & BLG B & BLG A & BLG B & BLG A & BLG B \\
\hline Study & 0.36 & 0.41 & 0.04 & 0.04 & 0.14 & 0.16 \\
\hline Placebo & 0.42 & 0.53 & 0.07 & 0.08 & 0.13 & 0.15 \\
\hline
\end{tabular}

* Values are geometric means; differences between study and placebo group were not statistically significant.

is this potentiation that results in the shortening of the duration of diarrhea.

Studying the local immune response of the gut is complicated even with invasive methods such as duodenal fluid sampling, especially in sick infants. The ELISPOT assay, based on the maturation cycle of gut-associated lymphoid tissue-derived lymphocytes, provides an indirect measure of the local response. After initial contact with the antigen in the gut, these lymphocytes cycle through the peripheral blood to localize back to the intestine. It has been shown not only in experimental animals but also in humans that the cells appear in blood a week after antigen administration $(10-12,15)$. In addition, it has been demonstrated that the lymphocyte response can be measured in blood more consistently than the antibody response in either duodenal fluid or serum (10).

The age distribution as well as the ISC and BLG sASC responses at convalescence were similar in the study and placebo groups. Thus, it is unlikely that the measured dissimilarities of the immune defense could be explained by preexisting differences between the groups. The duration of diarrhea, clinical picture on admission, and rotavirus-specific immune responses indicate that the infection was equally severe in both groups. 
The intestinal mucosa constitutes a major host barrier against foreign antigens encountered by the enteral route. The predominant mucosal Ig is IgA. It is responsible for immune exclusion of luminal antigens and may dampen local inflammatory reactions (16). In this study, the rotavirus-specific immune response, as measured by the ELISPOT method, was manifest at convalescence, which is in keeping with studies in animals (4) and humans $(17,18)$. Previous animal studies support the notion that antibodies of $\operatorname{IgA}$ isotype in the intestinal lumen are crucial for recovery and protection from rotavirus infection (4).

It is interesting that Lactobacillus GG enhances the IgA response to rotavirus. The augmentation of the immune response by Lactobacillus GG is similar to the adjuvant action previously demonstrated for cholera toxin (19). Lactobacillus GG has been shown to adhere to a human colon carcinoma cell line (20) and to colonize the gastrointestinal tract (21). It has been demonstrated that the adherence properties of the cholera toxin B subunit are related to the intensity of the mucosal immune response $(22)$ and that colonization with commensal bacteria promotes the production of $\operatorname{IgA}(23)$. The most likely explanation for the enhancement of the IgA response is the adherent property of Lactobacillus GG. Lactobacillus GG may influence permeation of antigens through Peyer's patches, thereby stimulating the numerous IgA-committed B cell population therein (16).

The ISC response during diarrhea may reflect rapid recruitment of local nonspecific immune mechanisms to limit the spread of the infection. The specific response to BLG during diarrhea suggests that it is partly directed against dietary antigens concomitantly present within the gut. Intestinal permeability is acutely increased during a rotavirus infection (24), and a local immune response to bystander antigens may provide protection against sequelae of rotavirus diarrhea, i.e. protracted diarrhea (25) and gastrointestinal allergy (26). The abrupt effect of $\mathrm{Lac}$ tobacillus $\mathrm{GG}$ on the ISC response is in support of the hypothesis of adjuvant action, where a temporal closeness between antigen and adjuvant administration is crucial (27), whereas the effect on the intensity of the response may be attributed to its adherent quality.

In conclusion, it is suggested that Lactobacillus GG may be a beneficial supplement of nutritional therapy of acute gastroenteritis in that it promotes recovery and gut immune defense mechanisms.

Acknowledgment. The authors thank Sinikka Suur-Nuuja for excellent technical assistance in determination of serum antibodies to milk proteins.

\section{REFERENCES}

1. Flores J, Nakagomi O, Nakagomi T, Glass R, Gorziglia M, Askaa J, Hoshino Y, Perez-Schael I, Kapikian AZ 1986 Role of rotaviruses in pediatric diarrhea. Pediatr Infect Dis J 5:S53-S62

2. Uhnoo IS, Freihorst J, Riepenhoff-Talty M, Fisher JE, Ogra PL 1990 Effect of rotavirus infection and malnutrition on the uptake of a dietary antigen in the intestine. Pediatr Res 27:153-160

3. Vaisman N, Hahn T, Dayan J, Schattner A 1990 The effect of different nutritional states on cell-mediated cytotoxicity. Immunol Lett 24:37-42
4. Uhnoo I, Dharakul T, Riepenhoff-Talty M, Ogra PL 1988 Festschrift: immunological aspects of interaction between rotavirus and the intestine in infancy. Immunol Cell Biol 66:135-145

5. Brown KH, MacLean WC 1984 Nutritional management of acute diarrhea: an appraisal of the alternatives. Pediatrics 73:119-125

6. Isolauri E, Juntunen M, Wiren S, Vuorinen P, Koivula T 1989 Intestinal permeability changes in acute gastroenteritis: effects of clinical factors and nutritional management. J Pediatr Gastroenterol Nutr 8:466-473

7. Isolauri E, Juntunen M, Rautanen T, Sillanaukee P, Koivula T 1991 A human Lactobacillus strain (Lactobacillus $\mathrm{GG}$ ) promotes recovery from acute diarrhea in children. Pediatrics 88:90-97

8. Kantele AM, Takanen R, Arvilommi H 1988 Immune response to acute diarrhea seen as circulating antibody-secreting cells. J Infect Dis 158:10111016

9. Kantele A, Arvilommi H, Jokinen I 1986 Specific immunoglobulin-secreting human blood cells after peroral vaccination against Salmonella typhi. J Infect Dis 153:1126-1131

10. Forrest BD 1988 Identification of an intestinal immune response using peripheral blood lymphocytes. Lancet 1:81-83

11. Czerkinsky C, Svennerholm A-M, Quiding M, Jonsson R, Holmgren J 1991 Antibody-producing cells in peripheral blood after oral cholera vaccination of humans. Infect Immun 59:996-1001

12. Lycke N, Lindholm L, Holmgren J 1985 Cholera antibody production in vitro by peripheral blood lymphocytes following oral immunization of humans and mice. Clin Exp Immunol 62:39-47

13. Isolauri E, Virtanen E, Jalonen T, Arvilommi H 1990 Local immune response measured in blood reflects the clinical reactivity of children with cow's milk allergy. Pediatr Res 28:582-586

14. Isolauri E, Suomalainen $H$, Kaila M, Jalonen $T$, Soppi E, Virtanen E, Arvilommi H 1992 Local immune response in cow milk allergy: follow-up of patients retaining allergy or becoming tolerant. J Pediatr 120:9-35

15. Doe WF 1989 The intestinal immune system. Gut 30:1679-1685

16. Brandtzaeg P, Halstensen, Kett K, Kvale D, Rognum TO, Scott H, Sollid LM, Valnes K 1989 Immunobiology and immunopathology of human gut mucosa: humoral immunity and intraepithelial lymphocytes. Gastroenterology 97:1562-1584

17. Davidson GP, Russell JH, Kirubakaran CP 1983 Serum and intestinal immune response to rotavirus enteritis in children. Infect Immun 49:447-452

18. Grimwood K, Lund JS, Coulson BS, Hudson IL, Bishop RF, Barnes GL 1988 Comparison of serum and mucosal antibody responses following severe acute rotavirus gastroenteritis in young children. J Clin Microbiol 26:732738

19. Lycke N, Karlsson U, Sjolander A, Magnusson K-E 1991 The adjuvant action of cholera toxin is associated with an increased intestinal permeability for luminal antigens. Scand J Immunol 33:691-698

20. Elo S, Saxelin M, Salminen S 1991 Attachment of Lactobacillus casei strain GG to human colon carcinoma cell line Caco-2: comparison with other dairy strains. Lett Appl Microbiol 13:154-156

21. Saxelin M, Elo S, Salminen S, Vapaatalo H 1991 Dose response colonisation of faeces after oral administration of Lactobacillus casei strain GG. Microb Ecol Health Dis 4:209-214

22. Van Der Heijden PJ, Bianchi ATJ, Dol M, Pals JW, Stok W, Bokhout BA 1991 Manipulation of intestinal immune responses against ovalbumin by cholera toxin and its B subunit in mice. Immunology 72:89-93

23. Lodinova-Zadnikova $R$, Slavikova $M$, Tlaskalova-Hogenova $H$, Adlerberth $I$, Hanson LA, Wold A, Carlsson B, Svanborg C, Mellander L 1991 The antibody response in breast-fed and non-breast-fed infants after artificial colonization of the intestine with Escherichia coli O83. Pediatr Res 29:396399

24. Jalonen $T$, Isolauri E, Heyman M, Crain-Denoyelle A-M, Sillanaukee P, Koivula T 1991 Increased $\beta$-lactoglobulin absorption during rotavirus enteritis in infants: relationship to sugar permeability. Pediatr Res 30:290-293

25. Khoshoo V, Bhan MK, Jayashree S, Kumar R, Glass RI 1990 Rotavirus infection and persistent diarrhoea in young children. Lancet 2:1314-1315

26. Walker-Smith JA 1986 Food sensitive enteropathies. Clin Gastroenterol 15:5569

27. Lycke N, Holmgren J 1986 Strong adjuvant properties of cholera toxin on gut mucosal immune responses to orally presented antigens. Immunology 59:301-308 